\title{
Anatomical Characteristics of Deer and Sheep Lumbar Spines: Comparison to the Human Lumbar Spine
}

\author{
Características Anatómicas de la Columna Vertebral de Ciervos y Ovejas: \\ Comparación con la Columna Vertebral Humana
}

Yang Wang*; Ting Liu**; Liang-Song Song*; Zhi-Xin Zhang*; You-Qiong Li*** \& Lai-Jin Lu*

WANG, Y.; LIU, T.; SONG, L. S.; ZHANG, Z. X.; LI, Y-Q. \& LU, L. J. Anatomical characteristics of deer and sheep lumbar spines: Comparison to the human lumbar spine. Int. J. Morphol., 33(1):105-112, 2015.

SUMMARY: Deer and sheep spines are often used as models of the human spine. A prerequisite for the use of animal models is information regarding the interspecies differences in the parameters of general interest. This would clarify the limitations of each animal model and substantiate the applicability of the obtained results to humans. Since sufficient data appear to be currently unavailable, we sought to investigate the feasibility of using deer and sheep as animal models for studies on the human spine. The objective of this study was a thorough comparison of the anatomical parameters of deer and sheep spines with those of the human spine. We employed threedimensional reconstructions of computed tomography images, generated using figure analysis software, which facilitated quantitative analysis of the linear and curvature parameters and the geometric index of the vertebral bodies. Our findings represent a comprehensive database of the anatomical characteristics of the deer and sheep lumbar spines and their comparisons with those of the human lumbar spine. This study provides insight into the similarities and differences in the vertebral geometries between the human spine and the deer and sheep spines. We found that the differences are minimal and that they do not greatly compromise the utility of deer and sheep lumbar spines as models of the human lumbar spine.

KEY WORDS: Spine; Animal model; Comparative anatomy; Sheep; Deer; Human.

\section{INTRODUCTION}

The cadaveric human spine is the ideal model for biomechanical studies of the spine and for testing spinal implants; however, there a few limitations to its use. One such limitation is the difficulty in obtaining fresh human specimens, especially from the younger population. Another problem is the large variation in the geometry and mechanical properties of human specimens that are due to differences in age, sex, bone quality, and bone degenerative changes. Therefore, it is necessary to identify suitable animal models as alternatives to the cadaveric human spine. In the past, the spines of various quadrupeds, such as pig, calf, sheep, goat, and dog, have been used as alternative models (Gurwitz et al., 1993; Nagata et al., 1993; Scifert et al., 1999; Baramki et al., 2000; van Dijk et al., 2002; Wilcox et al., 2004; Nuckley et al., 2007; Seel \& Davies, 2007).

The advancement of spinal research depends on the progress achieved in laboratory- and animal-based scientific studies. Calf and sheep are the most frequently used animal models in spine research (Wilke et al., 1997; Sandén et al., 2001; Yildirim et al., 2006; Kettler et al., 2007). However, outbreaks of bovine spongiform encephalopathy, avian influenza, severe acute respiratory syndromes (SARS), and influenza A (HIN1), along with the related risk of the personnel working with potentially contaminated tissues, have made the selection of animal models for spine research more difficult than ever (Wells et al., 1998). In fact, because of these concerns, some countries have imposed strict regulations on the use of animal models for experimental work (MAFF, 1998).

Chinese Merino sheep, which are the progeny of a cross between an Australian Merino ram and Boer Wentz ewe, have the advantages of stable heredity and minimal inter-individual differences. Since they are easily available, Chinese Merino are currently considered the most suitable sheep for experiments in China. Similarly, adult deer (Cervus nippon Temminck) are considered useful alternative models

* Department of Hand Surgery, The First Hospital of Jilin University, Changchun, Jilin, China.

** Department of General Internal Medicine, The First Hospital of Jilin University, Changchun, Jilin, China.

*** Department of Anatomy, Norman Bethune Medical College, Jilin University, Changchun, Jilin, China. 
for studies of the human spine for the following reasons: (1) adult deer are comparable in size to adult humans; (2) deer are readily available for research purposes; (3) the animals exhibit stable heredity and minimal inter-individual differences; (4) the animals are generally healthy, making them good surgical candidates and resistant to infection; and (5) most importantly, deer have scarcely (if ever) been reported as carriers of prion diseases. An anatomical database on the linear measurements of the deer spine and a comparison with the human spine has been previously published (Kumar et al., 2000, 2002). However, knowledge of the similarities and differences between animal models and human spines is essential to interpret the results of studies using these models and to establish the research area each model is suitable for. To our knowledge, no data are currently available on the anatomical curvature parameters and morphometric index of sheep and deer spines or on the comparison of these parameters with the human spine. Accordingly, the purpose of this study was to summarize the similarities and differences between the anatomical characteristics of sheep (Chinese Merino) and deer $(C$. nippon Temminck) spines and those of the human spine. We also sought to define criteria for the selection of the appropriate animal model for in vitro and in vivo experiments on the lumbar spine.

\section{MATERIAL AND METHOD}

Spine specimens. Spinal samples were obtained from 5 each of adult does (age: 1.5 to 2 years; torso length: 75 to $95 \mathrm{~cm}$; weight: 75 to $80 \mathrm{~kg}$ ) and adult male Merino sheep (age: 1.5 to 2 years; torso length: 62 to $79 \mathrm{~cm}$; weight: 46 to $62 \mathrm{~kg}$ ). The animals were provided by the Experimental Animal Center of Jilin University (Changchun, Jilin Province, China) and were euthanized by the administration of a ketamine overdose before the collection of the spinal samples. Additionally, spines of 5 male human cadavers (age: 21 to 31 years; torso length: 168 to $177 \mathrm{~cm}$ ) were procured through the Department of Anatomy of Norman Bethune Medical College, Jilin University (Changchun, Jilin Province, China). All procedures involving cadaveric tissue samples conformed to the mandates of and were approved by the
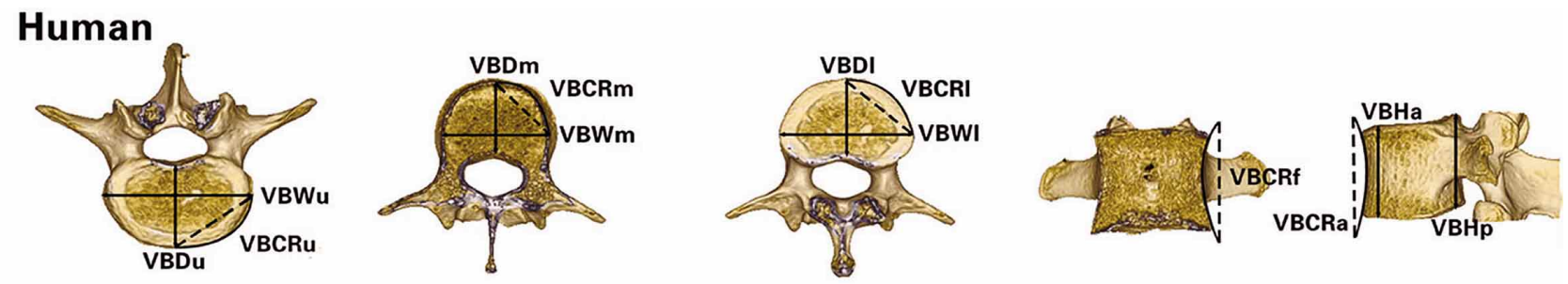

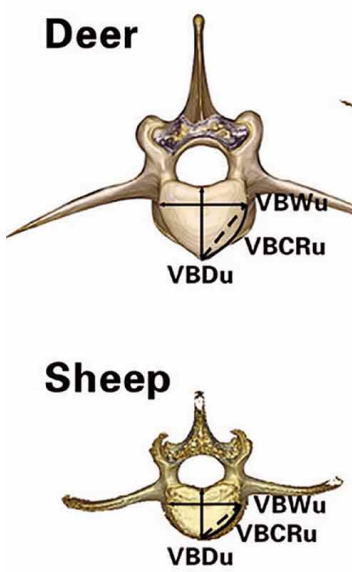

a

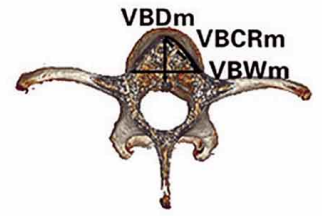

b
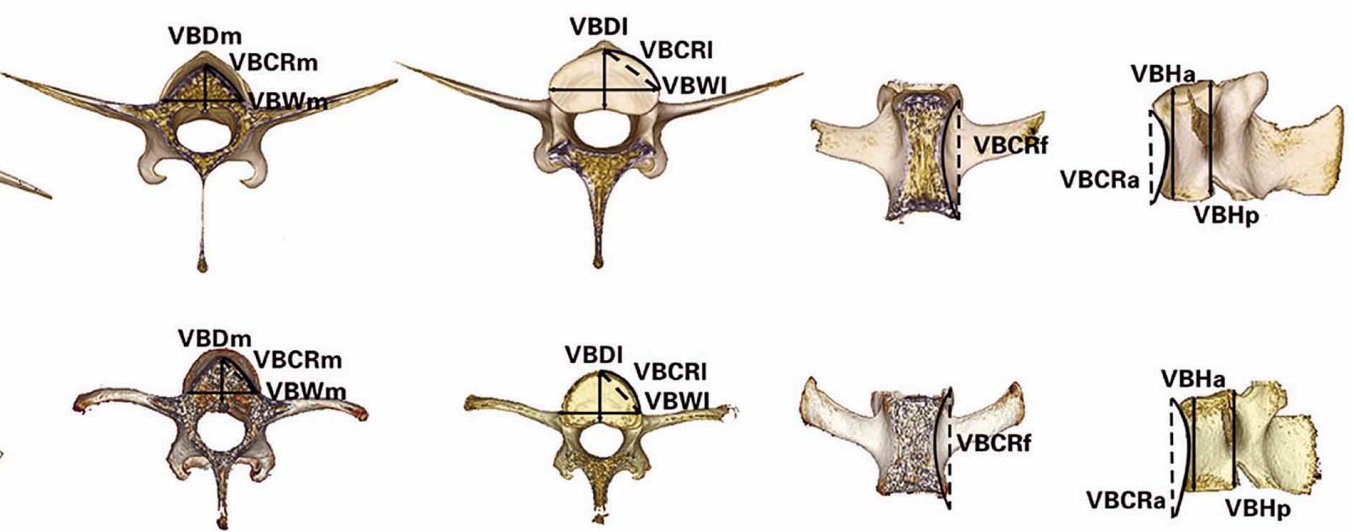

C d e

Fig. 1. Three-dimensional views of the lumbar vertebrae. The various measurements determined in the study are indicated here and further explained in Table I. (a) shows the superior view of the vertebrae and VBCRu refers to the curvature radius of the upper endplate of the vertebral body; (b) shows the middle cross-section view of the vertebrae and VBCRm refers to the curvature radius of the middle cross-section of the vertebral body; (c) shows the inferior view of the vertebrae and VBCRl refers to the curvature radius of the lower endplate of vertebral body; (d) shows the coronal-section view of the vertebrae and VBCRf refers to the curvature radius of the flank of vertebral body; (e) shows the lateral view of the vertebrae and VBCRa refers to the curvature radius of the anterior of vertebral body. Both VBCRa and VBCRf reflect the lateral-wall curvature of the vertebral body. 
Jilin University Ethics Committee; all procedures used with the cadavers and resected tissues were designed and performed in accordance with the national standards for use of human tissue (People's Republic of China Ministry of Health, 1994; People's Republic of China State Department, 2004). All protocols used with the animals were designed and performed in accordance with the principles of laboratory animal care and the current law and national standards on the protection of animals (People's Republic of China National Science and Technology Committee, 1988, 1997; People's Republic of China Ministry of Health, 1989; People's Republic of China National Standards, 1995).

While deer, sheep, and human spines are comparable in the lumbar regions, with minimal differences, obvious differences exist in the cervical and upper thoracic regions (Wilke et al.; Kumar et al., 2000). Therefore, we only analyzed the lumbar vertebrae in this study. For all spines, intact lumbar specimens (L1 to L6 of deer and sheep and L1 to L5 of humans) were removed en bloc, along with the associated muscles, soft tissues, and intervertebral discs. Each of the specimens was then radiographed to rule out any obvious bone lesions.

Computed tomography imaging. All specimens were scanned using a helical computed tomography (CT) scanner (LightSpeed 16; GE Medical Systems, Milwaukee, WI, USA), with the following specifications: $120 \mathrm{kVp} ; 320 \mathrm{~mA}$; $512 ¥ 512$ matrix; and slice thickness, $0.625 \mathrm{~mm}$. All images were retrieved on the CT workstation (Advantage
Workstation 4.3; GE Medical Systems) and were reformatted by three-dimensional (3D) reconstruction. The 3D models of the specimens could be rotated, cut, clipped, and measured. To minimize any errors occurring during these processes, a systematic and unified standard was used (Fig. 1).

Measurement of linear and curvature dimensions. The image analysis software Efilm Workstation (Merge Healthcare, Hartland, WI, USA) was used for quantitative measurements of the linear, curvature, and area parameters. The parameters measured have been explained diagrammatically in Figure 1 and the abbreviations expanded in Table I. The same anatomical landmarks were used across all measurements to ensure the accuracy of the measurements (Fig. 1) (Wilke et al.; Kumar et al., 2000).

\section{RESULTS}

The lumbar regions of the deer, sheep, and human spines were compared for the anatomical parameters mentioned in Table I; the results are presented in Table II. Additionally, we compared the morphometric index and endplate surface areas (ESAs) of the deer, sheep, and human spines in the lumbar regions (Table III).

Linear dimensions. In the human lumbar spine, the anterior vertebral body height ( $\mathrm{VBHa}$ ) increased steadily from $24.3 \pm 1.72 \mathrm{~mm}$ (L1) to $27.0 \pm 1.75 \mathrm{~mm}$ (L5), while that of

Table I. Anatomical parameters and their abbreviations used in this paper.

\begin{tabular}{lcl}
\hline \multirow{3}{*}{ Vertebral } & Abbreviation & \multicolumn{1}{c}{ Dimension } \\
body & VBD & Vertebral body depth \\
& VBW & Vertebral body width \\
& VBH & Vertebral body height \\
VBCR & Vertebral body curvature radius \\
& VBVI & Vertebral body vertical index ${ }^{\mathrm{a}}=(\mathrm{VBHp} / \mathrm{VBHa}) \times 100$ \\
& VBHI & Vertebral body horizontal index ${ }^{\mathrm{b}}=(\mathrm{VBD} / \mathrm{VBW}) \mathrm{x} 100$ \\
Suffices & ESA & Endplate surface area \\
& $\mathrm{U}$ & Upper \\
& $\mathrm{M}$ & Middle \\
& $\mathrm{L}$ & Lower \\
& $\mathrm{A}$ & Anterior \\
$\mathrm{P}$ & Posterior \\
& F & Flank
\end{tabular}

(a) When the value is less than 97.9 , the vertebral body is considered to be of the dorsosphenocentric type (DT). When the value is between 98.0 and 101.9, the vertebral body is considered to be of the orthosphenocentric type (OT). When the value is greater than 102.0, the vertebral body is considered to be of the ventrosphenocentric type (VT).

(b) When the value is less than 60 , the vertebral body is considered to be of the triangle shape (TS). When the value is between 60 and 80 , the vertebral body is considered to be of the kidney shape (KS). When the value is between 80 and 90, the vertebral body is considered to be of the heart shape (HS). When the value is greater than 90 , the vertebral body is considered to be of the circular shape (CS). 


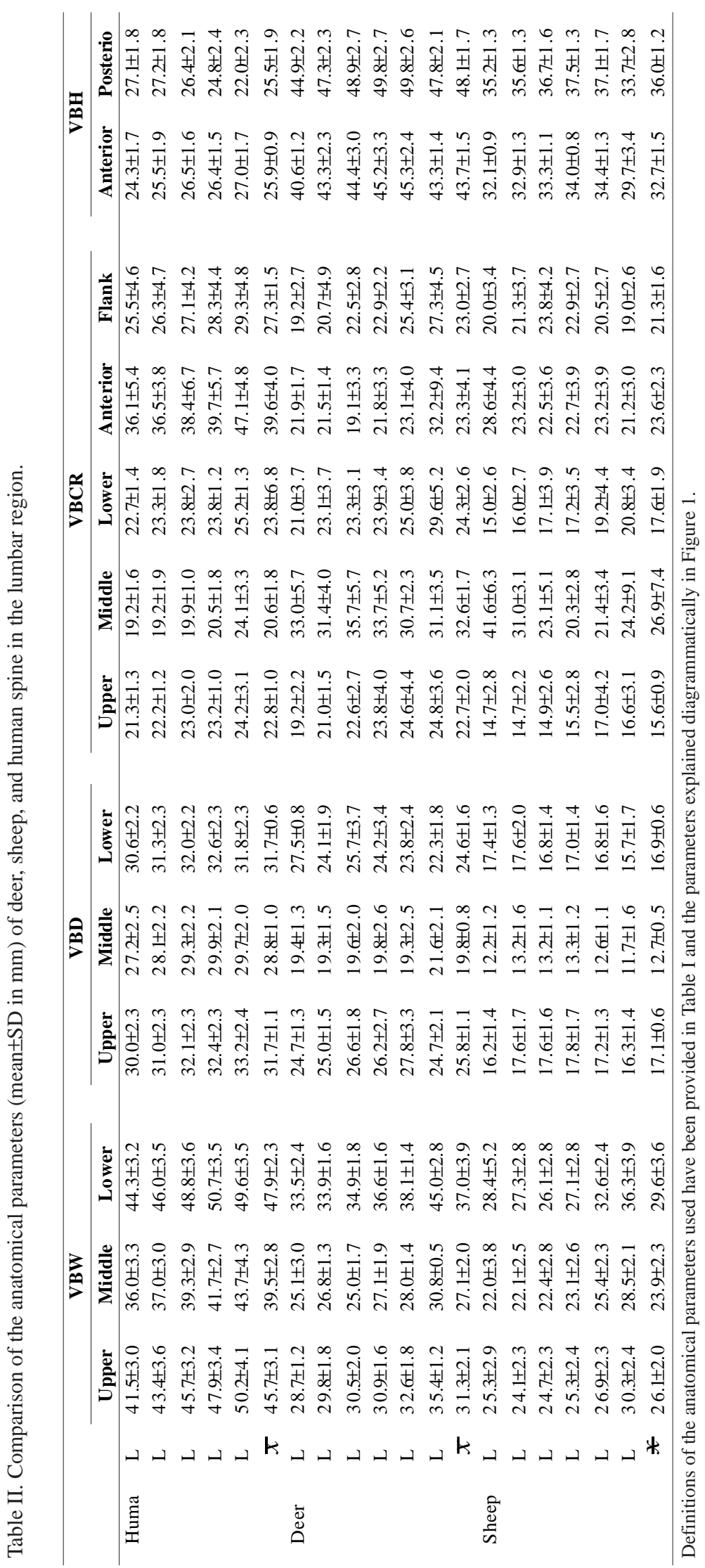

posterior vertebral body (VBHp) decreased from $27.1 \pm 1.89 \mathrm{~mm}$ (L1) to $22.0 \pm 2.30 \mathrm{~mm}(\mathrm{~L} 5)$. On the other hand, in deer and sheep, both the VBHa and VBHp increased caudally from L1 (40.6 \pm 1.29 $\mathrm{mm}$ and $32.1 \pm 0.97 \mathrm{~mm}$, respectively) to L5 $(45.3 \pm 2.46 \mathrm{~mm} ; 34.4 \pm 1.32 \mathrm{~mm}$, respectively) and then decreased to L6 $(43.3 \pm 1.48 \mathrm{~mm}$ and $29.7 \pm 3.45 \mathrm{~mm}$, respectively). These values indicate that the vertebral bodies in deer were taller than those in humans and sheep (Table II).

In the human lumbar spine, the width of the upper vertebral body (VBWu), similar to that of the lower (VBWl) and middle (VBWm) vertebral bodies, increased gradually from L1 to L5. A similar trend was observed in the case of deer and sheep lumbar spines. Further, the VBWm was consistently lesser than the VBWu and VBWl in all the three kinds of lumbar spines. These findings showed that the VBW in deer spine was greater than that in the sheep and lesser than that in humans at each level (Table II).

The vertebral body depth (VBD) was the least of the vertebral body dimensions in humans. In the human lumbar spine, the upper vertebral body depth (VBDu), middle VBD (VBDm), and lower VBD (VBDl) increased gradually, ranging from $30.0 \pm 2.38 \mathrm{~mm}$ (L1) to $33.2 \pm 2.24 \mathrm{~mm}$ (L5), $27.2 \pm 2.50 \mathrm{~mm}$ (L1) to $29.9 \pm 2.19 \mathrm{~mm}$ (L4), and $30.6 \pm 2.27 \mathrm{~mm}$ (L1) to $32.6 \pm 2.37 \mathrm{~mm}$ (L4), respectively. In deer, the VBDu increased from L1 $(24.7 \pm 1.37 \mathrm{~mm})$ to $\mathrm{L} 5(27.8 \pm 3.33 \mathrm{~mm})$ and decreased to L6 (24.7 $\pm 2.10 \mathrm{~mm}$ ), while the VBD1 decreased gradually from L1 to L6. For the sheep lumbar spine, the VBDu and VBDm increased to $\mathrm{L} 4$ and then decreased to $\mathrm{L} 6(\mathrm{~L} 1,16.2 \pm 1.47 \mathrm{~mm}$ and $12.2 \pm 1.20 \mathrm{~mm} ; \mathrm{L} 4,17.8 \pm 1.70 \mathrm{~mm}$ and $13.3 \pm 1.27 \mathrm{~mm}$; and L6, $16.3 \pm 1.48 \mathrm{~mm}$ and $11.7 \pm 1.61 \mathrm{~mm}$, respectively), while the VBDl decreased from $17.4 \pm 1.32 \mathrm{~mm}$ (L1) to $15.7 \pm 1.79$ $\mathrm{mm}$ (L6).

Curvature dimensions. The vertebral body curvature radius (VBCR) in human lumbar spine increased from L1 to L5 in all the views (VBCRu, VBCRm, VBCRl, VBCRa, and VBCRf). The VBCRu and VBCRl in the deer and sheep spines also showed a similar trend of increase from L1 to L5, whereas the VBCRm showed the opposite trend. The VBCRa in deer lumbar spine decreased from L1 (21.9 $\pm 1.74 \mathrm{~mm})$ to $\mathrm{L} 3(19.1 \pm 3.36 \mathrm{~mm})$ and then increased to L6 $(32.2 \pm 9.44 \mathrm{~mm})$, while 
the VBCRf increased from L1 $(25.5 \pm 4.68 \mathrm{~mm})$ to $\mathrm{L} 4(29.3 \pm 4.80 \mathrm{~mm})$ and then decreased to L6 (22.9 $\pm 2.26 \mathrm{~mm})$. The VBCRa and VBCRf in the sheep spine showed a trend similar to that in the deer spine.

Morphometric index. In humans, the vertebral body vertical index (VBVI) decreased from 111.5 (L1) to 81.5 (L5) (L1 and L2 were of the ventrosphenocentric type; L3, of the orthosphenocentric type; and L4 and L5, of the dorsosphenocentric type). The corresponding figures for deer and sheep spines ranged from 109.2 (L2) to 110.6 (L1) and from 108.2 (L2) to 113.5 (L6), respectively, thereby indicating that the deer and sheep vertebral bodies were of the ventrosphenocentric type at all levels. The vertebral body horizontal index (VBHI) in humans was fairly uniform at all levels, ranging from 64.1 (L5, lower) to 75.9 (L2, middle), and corresponding to the kidney shape. In deer, the values of the VBHI

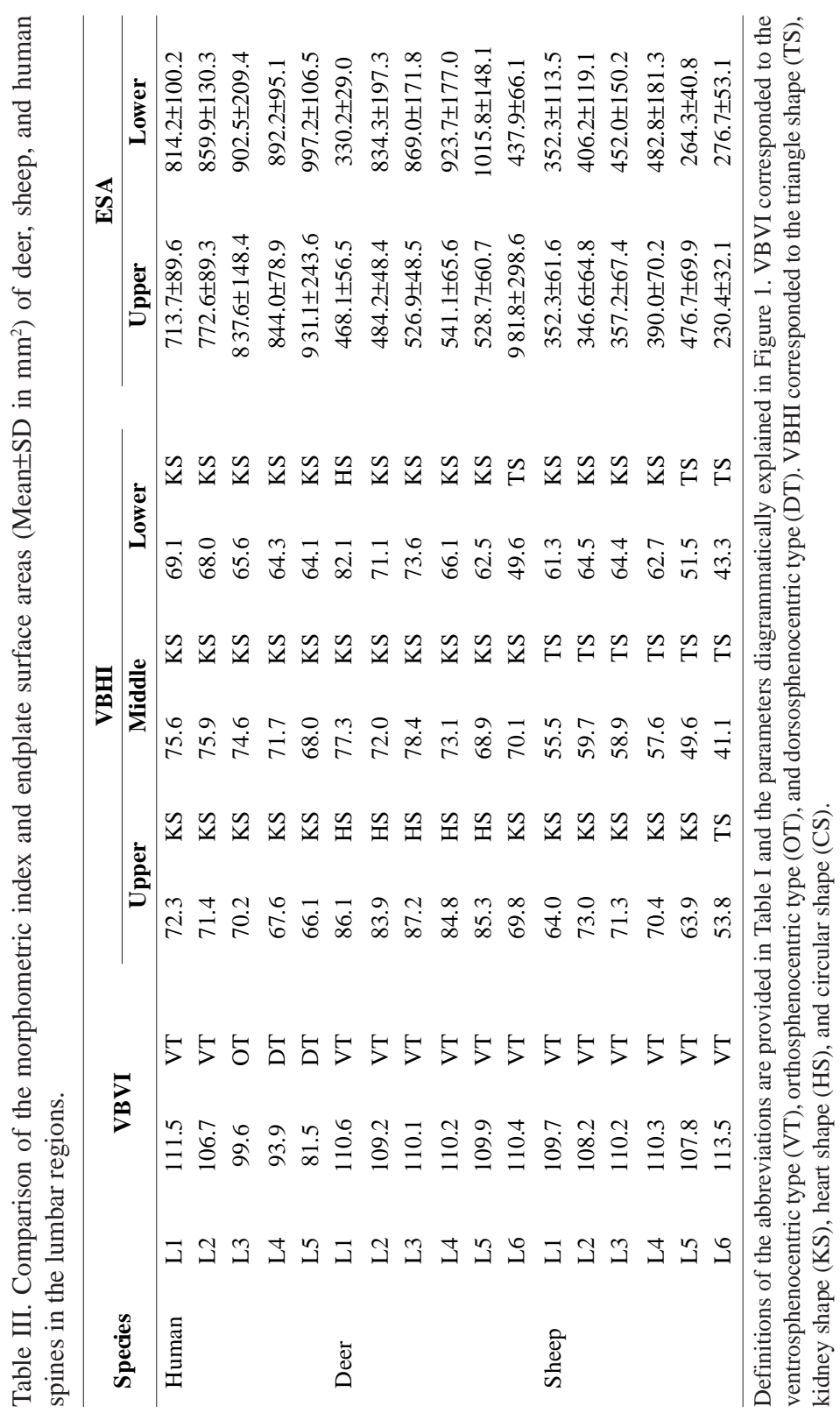

of the upper layer (VBHIu) were fairly concentrated in the range from 83.9 to 87.2. Additionally, the VBHIm and VBHIl in deer showed trends similar to those in human, indicating that the vertebral bodies in the upper layer were heart-shaped, while those in the middle and lower layers were kidney-shaped. The VBHIu and VBHIl in the sheep lumbar spine corresponded to the kidney shape, whereas the VBHIm (ranging from 41.1 to 59.7) corresponded to the triangle shape.

Endplate surface areas. ESA in humans increased from L1 to L5, in both upper $\left(713.7 \pm 89.6 \mathrm{~mm}^{2}\right.$ at $\mathrm{L} 1$ to $931.1 \pm 243.6 \mathrm{~mm}^{2}$ at L5) and lower $(814.2 \pm 100.2$ $\mathrm{mm}^{2}$ at $\mathrm{L} 1$ to $997.2 \pm 106.5 \mathrm{~mm}^{2}$ at L5) levels, and the upper ESA (ESAu) was less than the lower ESA (ESAl). The ESAu in sheep ranged from 476.7 \pm 69.9 $\mathrm{mm}^{2}$ (L5) to $230.4 \pm 32.2 \mathrm{~mm}^{2}$ (L6), while ESAl ranged from $482.8 \pm 181.3 \mathrm{~mm}^{2}$ (L4) to $264.3 \pm 40.8$ $\mathrm{mm}^{2}$ (L5). The ESA in the sheep spine was consistently lower than that in the human spine throughout the lumbar region. In deer too, the ESA values were comparable to those of the human and showed a similar trend. ESA increased gradually from L1 $\left(468.1 \pm 56.5 \mathrm{~mm}^{2}\right)$ to $\mathrm{L} 5\left(528.7 \pm 60.7 \mathrm{~mm}^{2}\right)$ in the upper layer and from L1 $\left(330.2 \pm 29.0 \mathrm{~mm}^{2}\right)$ to L5 $\left(1015.8 \pm 148.1 \mathrm{~mm}^{2}\right)$ in the lower layer. There were minor differences in the ESAl between deer and humans. These figures showed that the ESA in the human spine was consistently greater than that in the sheep spine and comparable to that in the deer spine (Table III).

\section{DISCUSSION}

Basic spine research and preclinical testing of new surgical methods often require animal experiments because most tests cannot be conducted on humans and because the availability of human specimens is limited. When using animal models, it is necessary to carefully study the similarities and differences between the anatomical characteristics of the animal models with respect to the parameters of interest. This will shed light on the limitations of a given animal model and enable the proper application of the obtained results to humans. The results of the current study provide a database for the spinal anatomy of 1.5 to 2-year-old deer (C. nippon Temminck) and sheep (Chinese Merino). We have separately discussed our findings for each parameter and sought to define the criteria for 
the selection of the appropriate animal model for different areas of research.

Linear dimensions. A fundamental difference among the species is that the human vertebra characteristically has a width (VBW) that is almost twice the height (VBH), whereas the deer and sheep vertebra have more height than width. With regard to the lumbar spine, the human vertebrae are larger in terms of their width and depth, which increased from L1 to L5. This makes the ESA in the human lumbar spine greater than that in the deer and sheep lumbar spine. This difference is most marked in the lower lumbar region. The biomechanical function of the spine in humans is vastly different from those in deer and sheep. Since deer and sheep are quadrupedal, their spines primarily bear load along a single horizontal axis, without marked transfer of stress along a vertical axis, as in the case of the human spine. This difference in function accounts for the gradual decrease in the $\mathrm{VBH}$ and increase in VBW and VBD in humans. Importantly, the similarities in the anatomical linear dimensions of deer and human vertebrae are greater than those of sheep and human vertebrae, suggesting that the deer may be the more suitable model of the lumbar spine.

Curvature dimensions. The curvature radius was comparable in the spines of all the three species. Similarities between the deer, sheep, and human lumbar vertebrae were the greatest for the measurement of the VBCR (Table II). The VBCRu and VBCRl in sheep spine were slightly less than those in the human spine and comparable to those in the deer spine. However, the lateral wall curvature of the vertebral body (VBCRa and VBCRf) varied markedly among the 3 species, with the values in the human spine being markedly greater than those in the deer and sheep spines. Accordingly, the relative contribution of the shell to the load-bearing ability of the vertebra decreased with increasing lateral wall curvature (Overaker et al., 1999). Overall, the differences in the curvature of the lateral wall of the vertebral body reflect the fact that in the human spine, cancellous bone plays a more important role than cortical bone in the load bearing of the lumbar vertebrae, as shown previously (Wang et al., 2010).

Morphometric index and endplate surface areas. Differences between the VBVI in the three species were noted in varying degrees. The deer and sheep spines show kyphosis to a small extent in the lumbar region. This is in contrast with the human spine, which shows lordosis in the lumbar region, reflecting the fact that humans are biped while deer and sheep are quadrupeds. In the human spine, the VBHI corresponded to the kidney shape for both the endplates and the middle crosssection. However, in deer spine, the VBHI corresponded to the heart shape in upper endplate and the kidney shape in middle cross-section and lower endplate. In the sheep spine, the VBHI corresponded to the kidney shape in the upper and lower endplates and the triangular shape in the middle crosssection. Our results support the fact that the vertebral body of the human lumbar spine is cylindrical, with slight narrowing in the middle section. On the other hand, the vertebral body of deer was semi-cylindrical and gradually transitioned towards the cylindrical shape along the vertical axis. The vertebral body of the sheep spine also showed a cylindrical shape, transitioning into a triangular prism shape in the middle crosssection. The deer spine was comparable to the human spine with respect to the ESAs in the lumbar region, while the sheep spine was similar to the human spine in terms of the vertebral body geometry.

On the basis of the comparative data of these animal models alone, it is difficult to interpret whether a given species is suitable for use as an alternative to the cadaveric human spine. Nevertheless, we can select the appropriate animal model for different topics of research according to criteria such as linear dimension, curvature dimension, geometrical morphology, and ESA. In the light of our findings, we suggest that the deer lumbar spine may be the more suitable model of the human lumbar spine for studies on the biomechanics of interbody cages, because of the similarities between the two kinds of spines in the linear dimension, curvature dimension, and ESAs. On the other hand, the sheep lumbar spine may be more suitable for biomechanical experiments concerning the pedicle screw systems, considering the similarity in the vertebral body geometry of sheep and humans.

Our study has some drawbacks. First, the sample size in this study is small. To overcome this deficiency, deer and sheep spine specimens were strictly selected such that they were of similar age, torso length, and weight. We believe that the establishment of rigorous standards for screening experimental animals will help reduce and refine the expenditure of experimental animals, in accordance with the 3R-principle (reduction, replacement, and refinement) (Russell \& Burch, 1959). More importantly, the small values of the SD of the anatomical parameters show that the experimental results are stable. Our study provides a thorough anatomical database of the lumbar spinal vertebrae of deer and sheep and detailed information on the similarities and differences in the vertebral geometries of deer and sheep lumbar spines and the human lumbar spine. The differences were found to be minimal and did not affect the validity of deer and sheep lumbar spine as suitable models of the lumbar spine.

In conclusion, our morphometric analyses show that both deer and sheep lumbar spines represent viable options for use as models of the human lumbar spine. Our data may also facilitate the selection of the appropriate animal model for different areas of focus in spinal research. 
ACKNOWLEDGMENTS. The authors thank the Experimental Animal Center of Jilin University for providing the deer and sheep spine specimens. In addition, the authors wish to express gratitude toward the Department of Anatomy of Jilin University for providing the fresh cadavers and the workspace for conducting the study. The authors are also grateful to the Department of Radiology of China-Japan Union Hospital of Jilin University for allowing use the helical CT scanner. We thank Medjaden Bioscience Limited for assisting in the preparation of this manuscript.

WANG, Y.; LIU, T.; SONG, L. S.; ZHANG, Z. X.; LI, Y-Q. \& LU, L. J. Características anatómicas de la columna vertebral de ciervos y ovejas: Comparación con la columna vertebral humana. Int. J. Morphol., 33(1):105-112, 2015.

RESUMEN: La columna vertebral de ciervos y ovejas se utiliza frecuentemente como modelo de la columna vertebral humana. Un requisito previo para el uso de modelos animales es la información con respecto a las diferencias entre especies en los parámetros de interés general, lo que aclara las limitaciones de cada modelo animal y fundamenta la aplicabilidad de los resultados obtenidos para los seres humanos. Debido a que existen datos suficientes actualmente, hemos intentado investigar la viabilidad de utilizar ciervos y ovejas como modelos animales para los estudios sobre la columna vertebral humana. El objetivo fue realizar una comparación exhaustiva de los parámetros anatómicos de las columnas de ciervos y ovejas, con los de la columna vertebral humana. Empleamos reconstrucciones tridimensionales de imágenes de tomografía computadorizada, mediante un programa de análisis de la figura, lo que facilitó el análisis cuantitativo de los parámetros lineales y de la curvatura y el índice geométrico de las vértebras. Nuestros hallazgos representan una amplia base de datos de las características anatómicas de la columna lumbar de los ciervos y ovejas y sus comparaciones con las de la columna lumbar humana. Este estudio proporciona información sobre las similitudes y diferencias en las geometrías vertebrales entre la columna vertebral humana y las columnas de venado y oveja. Se encontró que las diferencias son mínimas y que no comprometen el uso de la columna de ciervos y ovejas como modelos de la columna lumbar humana.

PALABRAS CLAVE: Columna vertebral; Modelo animal; Anatomía comparativa; Oveja; Ciervo; Humano.

\section{REFERENCES}

Baramki, H. G.; Steffen, T.; Lander, P.; Chang, M. \& Marchesi, D. The efficacy of interconnected porous hydroxyapatite in achieving posterolateral lumbar fusion in sheep. Spine (Phila Pa 1976), 25(9):1053-60, 2000.

Gurwitz, G. S.; Dawson, J. M.; McNamara, M. J.; Federspiel, C. F. \& Spengler, D. M. Biomechanical analysis of three surgical approaches for lumbar burst fractures using shortsegment instrumentation. Spine (Phila Pa 1976), 18(8):977$82,1993$.

Kettler, A.; Liakos, L.; Haegele, B. \& Wilke, H. J. Are the spines of calf, pig and sheep suitable models for pre-clinical implant tests? Eur. Spine J., 16(12):2186-92, 2007.

Kumar, N.; Kukreti, S.; Ishaque, M. \& Mulholland, R. Anatomy of deer spine and its comparison to the human spine. Anat. Rec., 260(2):189-203, 2000.

Kumar, N.; Kukreti, S.; Ishaque, M.; Sengupta, D. K. \& Mulholland, R. C. Functional anatomy of the deer spine: an appropriate biomechanical model for the human spine? Anat. Rec., 266(2):108-17, 2002.

Ministry of Agriculture Fisheries and Food (MAFF). Bovine spongiform encephalopathy in Great Britain. A progress report. London, Ministry of Agriculture, Fisheries, and Food, 1998.

Nagata, H.; Schendel, M. J.; Transfeldt, E. E. \& Lewis, J. L. The effects of immobilization of long segments of the spine on the adjacent and distal facet force and lumbosacral motion. Spine (Phila Pa 1976), 18(16):2471-9, 1993.

Nuckley, D. J.; Van Nausdle, J. A.; Eck, M. P. \& Ching, R. P. Neural space and biomechanical integrity of the developing cervical spine in compression. Spine (Phila Pa 1976), 32(6):E181-7, 2007.

Overaker, D. W.; Langrana, N. A. \& Cuitiño, A. M. Finite element analysis of vertebral body mechanics with a nonlinear microstructural model for the trabecular core. J. Biomech, Eng., 121(5):542-50, 1999.

People's Republic of China National Science and Technology Committee. The regulations of experimental animals. Beijing, State Science and Technology Commission, 1988.

People's Republic of China Ministry of Health. Administrative rules of experimental animals. Beijing, Ministry of Health, 1989.

People's Republic of China Ministry of Health. Regulations for medical institutions. Beijing, Ministry of Health, 1994.

People's Republic of China National Standards. Publishing house of China standards: experimental animals national standards. Beijing, State Science and Technology Commission, 1995.

People's Republic of China National Science and Technology Committee. Experimental animals national standards. Beijing, State Science and Technology Commission, 1997. 
WANG, Y.; LIU, T.; SONG, L. S.; ZHANG, Z. X.; LI, Y-Q. \& LU, L. J. Anatomical characteristics of deer and sheep lumbar spines: Comparison to the human lumbar spine. Int. J. Morphol., 33(I):105-112, 2015.

People's Republic of China State Department. Regulations for biosafety of pathogenic laboratories. Beijing, State Council, 2004.

Russell, W. M. S. \& Burch, R. L. The principles of Humane Experimental Technique. 1959. In: Baltimore, Johns Hopkins University, Bloomberg School of Public Health, 2014. Available in: http://altweb.jhsph.edu/pubs/books/humane_exp/ het-toc

Sandén, B.; Olerud, C. \& Larsson, S. Hydroxyapatite coating enhances fixation of loaded pedicle screws: a mechanical in vivo study in sheep. Eur. Spine J., 10(4):334-9, 2001.

Scifert, J. L.; Sairyo, K.; Goel, V. K.; Grobler, L. J.; Grosland, N. M.; Spratt, K. F. \& Chesmel, K. D. Stability analysis of an enhanced load sharing posterior fixation device and its equivalent conventional device in a calf spine model. Spine (Phila Pa 1976), 24(21):2206-13, 1999.

Seel, E. H. \& Davies, E. M. A biomechanical comparison of kyphoplasty using a balloon bone tamp versus an expandable polymer bone tamp in a deer spine model. J. Bone Joint Surg. Br., 89(2):253-7, 2007.

van Dijk, M.; Smit, T. H.; Sugihara, S.; Burger, E. H. \& Wuisman, P. I. The effect of cage stiffness on the rate of lumbar interbody fusion: an in vivo model using poly(l-lactic Acid) and titanium cages. Spine (Phila Pa 1976), 27(7):682-8, 2002.

Wang, Y.; Liu, G.; Li, T.; Xiao, Y.; Han, Q.; Xu, R. \& Li, Y. Morphometric comparison of the lumbar cancellous bone of sheep, deer, and humans. Comp. Med., 60(5):374-9, 2010.

Wells, G. A.; Hawkins, S. A.; Green, R. B.; Austin, A. R.; Dexter, I.; Spencer, Y. I.; Chaplin, M. J.; Stack, M. J. \& Dawson, M. Preliminary observations on the pathogenesis of experimental bovine spongiform encephalopathy (BSE): an update. Vet. Rec., 142(5):103-6, 1998.

Wilcox, R. K.; Allen, D. J.; Hall, R. M.; Limb, D.; Barton, D. C. \& Dickson, R. A. A dynamic investigation of the burst fracture process using a combined experimental and finite element approach. Eur. Spine J., 13(6):481-8, 2004.

Wilke, H. J.; Kettler, A.; Wenger, K. H. \& Claes, L. E. Anatomy of the sheep spine and its comparison to the human spine. Anat. Rec., 247(4):542-55, 1997.

Yildirim, O. S.; Aksakal, B.; Hanyaloglu, S. C.; Erdogan, F. \& Okur, A. Hydroxyapatite dip coated and uncoated titanium poly-axial pedicle screws: an in vivo bovine model. Spine (Phila Pa 1976), 31(8):E215-20, 2006.

\author{
Correspondence to: \\ Lai-Jin Lu \\ Department of Hand Surgery \\ The First Hospital of Jilin University \\ 71\# Xinmin Street \\ Changchun \\ Jilin 130021 \\ CHINA
}

Email: handsurgery2011@sina.com

Received: 07-07-2014

Accepted: 05-11-2014 